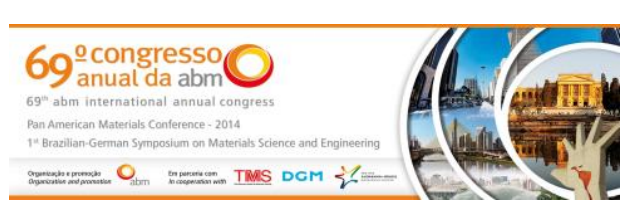

Tema: Gestão de Meio Ambiente e Recuperação e Tratamento de Rejeitos

\title{
RECUPERAÇÃO DE ALUMÍNIO PRESENTE NAS EMBALAGENS DE MEDICAMENTOS TIPO “BLISTER”*
}

\author{
Douglas Will Leite ${ }^{1}$ \\ Willian Naville ${ }^{2}$ \\ Domingos Theodoro Andrade Figueira Filho ${ }^{3}$ \\ Patricia Flygare Razo 4
}

\section{Resumo}

O objetivo deste estudo é recuperar parte do alumínio empregado na fabricação das embalagens de medicamentos do tipo "blister", por tratamento químico e térmico seguido de separação gravimétrica, resultando na obtenção de alumínio na forma de óxido $\left(\mathrm{Al}_{2} \mathrm{O}_{3}\right)$. A caracterização do produto particulado metálico obtido constitui-se em um caminho para se chegar ao patamar de existência de coleta seletiva após seu descarte, diminuição deste tipo de embalagens nos aterros sanitários e/ou incineradores de lixo doméstico e posterior reaproveitamento com amplos benefícios ambientais. A caracterização morfológica do óxido de alumínio obtido foi realizada utilizando as técnicas instrumentais de ICP/AES e MEV/EDS.

Palavras-chave: Reciclagem de Alumínio; Blister; Embalagens farmacêuticas.

\section{RECOVERY OF ALUMINUM PACKAGING OF DRUGS IN THIS TYPE "BLISTER"}

\begin{abstract}
The aim of this study is to recover part of the aluminum used in the manufacture of packaging for medicines like "blister", by chemical and thermal treatment followed by gravimetric separation, resulting in getting as aluminum oxide $\left(\mathrm{Al}_{2} \mathrm{O}_{3}\right)$. The characterization of metallic particulate product obtained is on a path to reach the level of existence of selective collection after his discharge, decrease in this type of packaging in the health and or household waste incinerators and later reuse with broad environmental benefits landfills. The morphological characterization of the obtained aluminum oxide was performed using the instrumental techniques ICP / AES and MEV / EDS.
\end{abstract}

Keywords: Aluminum Recycling; Blister; Pharmaceutical packaging.

1 Químico do Instituto de Pesquisas e Estudos Industriais, Centro Universitário da FEl, São Bernardo do Campo, SP, Brasil.

2 Prof. Depto. de Eng. Materiais, Centro Universitário da FEl, São Bernardo do Campo, SP, Brasil.

3 Prof. Depto. de Eng. Materiais, Centro Universitário da FEl, São Bernardo do Campo, SP, Brasil.

4 Tecnóloga, Sinterconsult Tecnologia S/C Ltda., São Paulo, SP, Brasil.

\footnotetext{
* Contribuição técnica ao 69ำ Congresso Anual da ABM - Internacional e ao 14ํㅡㄹ ENEMET - Encontro Nacional de Estudantes de Engenharia Metalúrgica, de Materiais e de Minas, 21 a 25 de julho de 2014, São Paulo, SP, Brasil.
} 


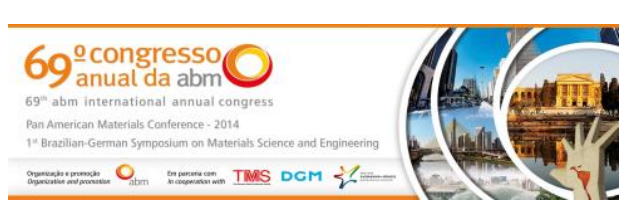

\section{INTRODUÇÃO}

O Alumínio é o elemento metálico mais abundante na crosta terrestre, estando entre os três de todos os elementos da natureza, após o oxigênio e o silício. A produção deste metal no Brasil na forma de lingotes teve início em 1945 e já na segunda metade do século XX ocorreu o desenvolvimento e a diversificação dos tipos de produtos acabados, chegando-se então ao alumínio na forma de folhas finas para embalagens [1].

"Blister" é o nome dado ao tipo de embalagem bastante utilizada nas indústrias farmacêuticas, que é confeccionada pela utilização de uma fina lâmina de material polimérico, normalmente o Policloreto de Vinila (PVC), o Policloreto de Vinilideno (PVDC) ou o Policlorotrifluoretileno (Aclar) em conjunto a uma folha de alumínio laminado conforme demonstrado na figura 1 [2]. Assim é obtida uma embalagem totalmente lacrada que evita a exposição do material embalado à ação degradante precoce causada pela oxidação ou umidade do ar.

O projetista Karl Klein, na Alemanha no início de 1960, apresentou o primeiro mecanismo para a produção avançada de embalagens tipo "blisters", vindo mais tarde dominar no segmento farmacêutico de comprimidos e pílulas devido a sua eficiência e praticidade [3].

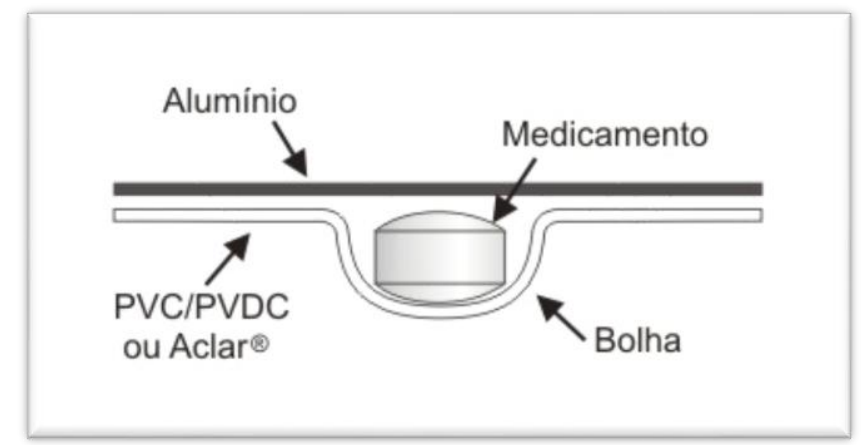

Fonte:http://commons.wikimedia.org/wiki/File:Blister_remedio.jpg[2].

Figura 1. Representação de uma embalagem tipo "blister".

Pode-se afirmar que o resultado da mistura destes materiais origina um material compósito [4], devido à presença de produtos de distintas propriedades físicas e químicas: o Alumínio, o PVC, o adesivo de fixação e a tinta de impressão para identificação.

Diversos estudos descrevendo diferentes maneiras para reaproveitar este tipo de embalagem sendo encontradas em literatura técnica especializada, sendo um exemplo interessante o método descrito por Castro [5], em pesquisa congênere e por Hidalgo [6], que envolve um processo de moagem deste compósito e utiliza a mistura obtida como carga aglomerante na produção de chapas e bobinas utilizadas para diversas aplicações na área da construção civil.

\section{MATERIAIS E MÉTODOS}

Amostras de embalagens tipo "blister" com variados formatos e tamanhos foram tomadas levando em conta cada porção de ensaio com massa de 25 gramas, separando-se aleatoriamente as embalagens, cortando-as em dois ou três pedaços para facilitar a pesagem. Feita a pesagem, as amostras foram alocadas em copos

\footnotetext{
* Contribuição técnica ao $69^{\circ}$ Congresso Anual da ABM - Internacional e ao 14ํㅡㄹ ENEMET - Encontro Nacional de Estudantes de Engenharia Metalúrgica, de Materiais e de Minas, 21 a 25 de julho de 2014, São Paulo, SP, Brasil.
} 


\subsection{Análise Química}

Análise química instrumental via Espectrometria de Emissão Atómica por Plasma Acoplado Indutivamente (ICP/AES) foi realizada com o objetivo de determinar os metais presentes no material particulado recolhido após a queima do papel de filtro e indicou o elemento ferro como principal contaminante. Os resultados são apresentados na tabela 2.

Tabela 2. Analise Química Instrumental via ICP/AES

\begin{tabular}{c|c|c|c|c}
\hline Amostras & Ca \% & Fe \% & Mn \% & Cu \% \\
\hline 01 & 0,13 & 6,45 & 0,11 & 0,03 \\
\hline 02 & 0,06 & 7,90 & 0,11 & 0,47 \\
\hline 03 & 0,10 & 7,09 & 0,14 & 0,15 \\
\hline 04 & 0,15 & 11,60 & 0,20 & 0,04 \\
\hline
\end{tabular}

Fonte: Laboratório de química do Instituto de Pesquisas do Centro Universitário da FEl.

Em seguida, as quatro amostras ilustradas na figura 3 foram reunidas e foi efetuada a determinação do teor de Alumínio via ICP. Como resultado foi obtido o valor de $10,5 \%$ de Alumínio, representando 2,93 g de $\mathrm{Al}_{2} \mathrm{O}_{3}$ para cada quilograma de "blister" processado.

(A)

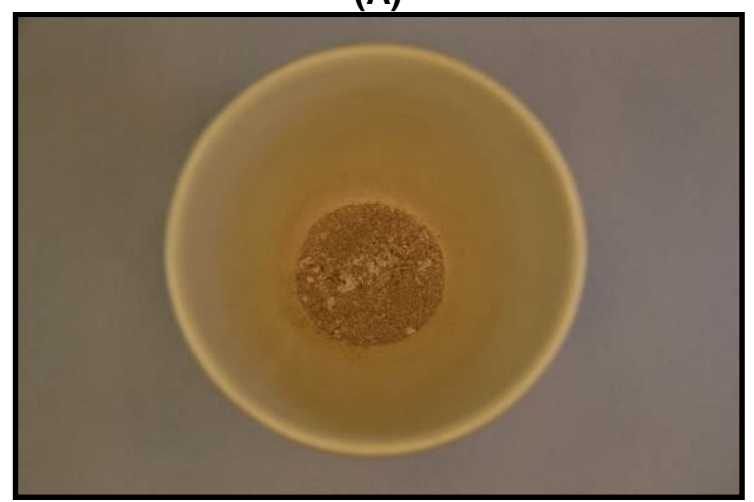

(B)

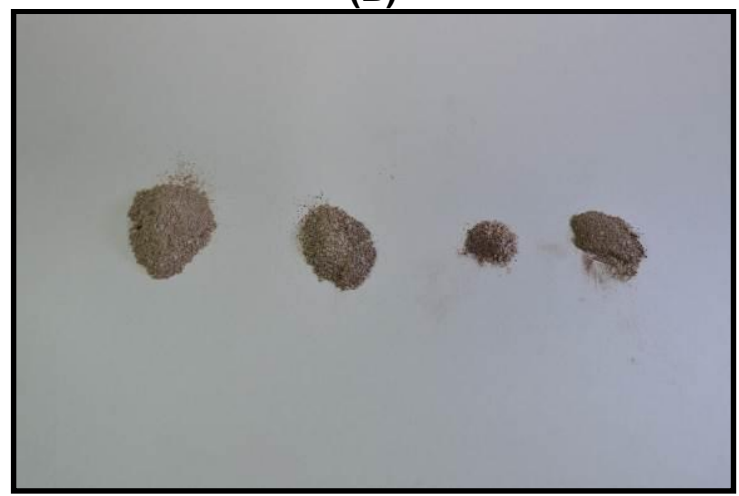

A) Após tratamento térmico, (B) Visa das quatro Figura 3. Imagens

\subsection{Análise da morfologia de partícula}

Para avaliação morfológica e microestrutural do material particulado recolhido após a queima do papel de filtro foi empregado um microscópio eletrônico de varredura (MEV) Marca CamScan 3200LV, obtendo-se as seguintes imagens apresentadas nas figuras 4 e 5 abaixo.

\footnotetext{
* Contribuição técnica ao 69ำ Congresso Anual da ABM - Internacional e ao 14ํㅡㄹ ENEMET - Encontro Nacional de Estudantes de Engenharia Metalúrgica, de Materiais e de Minas, 21 a 25 de julho de 2014, São Paulo, SP, Brasil.
} 


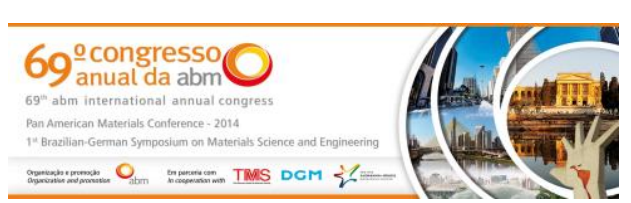

\section{CONCLUSÕES}

Os estudos realizados neste trabalho revelaram como rendimento a recuperação de $14,8 \mathrm{~g}$ de material sólido particulado para cada quilograma de "blister" reciclado. Este material sólido particulado, por sua vez, apresenta-se predominantemente como partículas tipo "flake ou escamas", tendo em sua composição 2,93g de óxido de alumínio $\left(\mathrm{Al}_{2} \mathrm{O}_{3}\right)$ e $1,55 \mathrm{~g}$ de alumínio puro. $\mathrm{O}$ ferro foi o principal elemento contaminante deste material sólido particulado obtido.

\section{Agradecimentos}

Centro de Laboratórios Mecânicos e Materiais do Centro Universitário da FEI. Sr. Airton Morassi pela sua atenção e prestatividade no auxilio para realização das imagens e a todos os técnicos do laboratório de materiais do CLM.

Aos Professores e colaboradores que contribuíram de forma direto ou indiretamente para conclusão desta pesquisa.

\section{REFERÊNCIAS}

1 Guia De Fornecedores De Produtos E Serviços Do Alumínio. Editora Segmento, pg. 1017, 2007.

2 <http://commons.wikimedia.org/wiki/File:Blister_remedio.jpg> Acesso em: 05 de junho 2013.

3 Ron Pilchik Pharmaceutical Blister Packaging, part 1, rationale and materials, Pharmaceutical Technology Nov. 2000.

4 Kaw AK Mechanic of Composite Materials, CRC Press Boca Raton New York 1997.

5 Castro ATP, Rossini EL, Silva LGA. Reaproveitamento de Embalagens Tipo "Blisters" Compostas por PVC e Alumínio, Instituto de Pesquisa Energética e Nuclear IPEN.

6 Hidalgo M. Manufacturing rigid board by packaging waste containing aluminum and polyethylene, Journal of Scientific \& Industrial Research, 2011;70:232-234.

7 Constantino VRL, Araki K, Silva DO, Oliveira W. Preparação de compostos de Alumínio a partir de Bauxita: Considerações sobre alguns aspectos envolvidos em um experimento didático, Química Nova, 2002;25(3):490-498.

8 A Metalurgia do Pó, Alternativa econômica com menor impacto ambiental. $1^{\circ}$ edição Metallum Eventos Técnicos SP 2009, pg. 131-135.

9 Klar E. Metals Handbook Ninth Edition, vol. 7 Powder Metallurgy, pg. 233-236, 1984.

* Contribuição técnica ao 69ำ Congresso Anual da ABM - Internacional e ao 14ํㅡㄹ ENEMET - Encontro Nacional de Estudantes de Engenharia Metalúrgica, de Materiais e de Minas, 21 a 25 de julho de 2014, São Paulo, SP, Brasil. 